Edith Cowan University

Research Online

Research outputs pre 2011

8-31-2007

Engaging Primary Health Care Providers in the Promotion of Healthy Weight Among Young Children: Barriers and Enablers for Policy and Management

\author{
Lydia A. Hearn \\ Edith Cowan University \\ Margaret R. Miller \\ Edith Cowan University \\ Donna S. Cross \\ Edith Cowan University
}

Follow this and additional works at: https://ro.ecu.edu.au/ecuworks

Part of the Public Health Commons

10.1071/PY07025

Hearn, L. A., Miller, M. R., \& Cross, D. S. (2007). Engaging primary health care providers in the promotion of healthy weight among young children: Barriers and enablers for policy and management. Australian Journal of Primary Health, 13(2), 66-79. https://doi.org/10.1071/PY07025

This Journal Article is posted at Research Online.

https://ro.ecu.edu.au/ecuworks/1624 


\section{Engaging Primary Health Care Providers in the Promotion of Healthy Weight among Young Children: Barriers and Enablers for Policy and Management}

\section{Authors:}

Lydia Hearn, EdD, MSc, BA(Hons)

Co-Director,

Child Health Promotion Research Centre

School of Exercise, Biological and Health Sciences

Edith Cowan University

Churchlands Campus,

Pearson Street,

WA 6018

Margaret Miller, M App Sc, Grad Dip Public Admin, Grad Dip Dietetics, BSc(Hons)

Project Director, Promoting Healthy Weight

Child Health Promotion Research Centre

School of Exercise, Biological and Health Sciences

Edith Cowan University

Churchlands Campus,

Pearson Street,

WA 6018

Donna Cross, EdD, Grad. Dip Health Science, B.Ed(Distinction)

Professor, Adolescent and Child Health,

Director, Child Health Promotion Research Centre

School of Exercise, Biological and Health Sciences

Edith Cowan University

Churchlands Campus,

Pearson Street,

WA 6018 


\begin{abstract}
Rationale: Recent national efforts to stem the alarming growth of childhood overweight and obesity in Australia, have highlighted the importance of preventative strategies that focus beyond the child, on parents, families, primary health care providers (PHCPs) and child care services. But, while such efforts have to date focused on school-based interventions once poor eating habits and sedentary lifestyles have set in, a growing body of research is indicating that PHCPs can play a more influential role in monitoring and modifying factors affecting prevention and early intervention in preschool children.

Methods: This paper presents the findings of a systematic review to: a) identify key barriers to the effective engagement of PHCPs with parents and child care staff in the promotion of healthy weight among children aged 2-6 years; b) appraise 'promising' interventions for strengthening the capacity of PHCPs to effectively deal with these barriers; and c) synthesise policy options to encourage and engage primary.

Conclusions: The study draws on the lessons of promising interventions to highlight the urgent need to address organisational, attitudinal, knowledge, skills and training barriers, to facilitate the engagement of PHCPs in different settings based environments (clinical, child care, home and community).
\end{abstract}




\section{The Extent and Impact of Childhood Obesity in Australia}

Overweight and obesity rates of Australian children are among the highest in the developed world (Australian Institute of Health and Welfare, 2003; Goodman, Lewis, Dixon, \& Travers, 2002; Wake, Salmon, Waters, Wright, \& Hesketh, 2002b; World Health Organization, 2000). National figures indicate that childhood obesity trebled in the decade between 1985 and 1995, with an estimated 20-25\% of children being overweight or obese (Australian Bureau of Statistics, 1995) - with a review of more recent independent surveys showing similar figures (Hearn, Miller, Campbell-Pope, \& Waters, 2006). This means that today an estimated 1.5 million Australian children under 18 years of age can be categorised as being overweight or obese (Commonwealth of Australia, 2005).

Yet more alarming is the steady rise among 'preschool' children, especially those from low socio-economic families. In 1995, national figures for 2 to 4 year olds indicated that $18.5 \%$ of girls and $14.6 \%$ of boys were overweight, while a further $4.2 \%$ of girls and $2.2 \%$ of boys were obese (Australian Bureau of Statistics, 1995). But, early data emerging from the new Longitudinal Study of Australian Children, suggests that the obesity level among this same age group has now risen to 6\% (Department of Family and Community Services, 2005). Such figures are echoed at the state level, with a South Australian study showing an increase in obesity levels among preschoolers between 1995 and 2002, from 3.5\% to $5.8 \%$ among girls and from $3.2 \%$ to $4.1 \%$ among boys, respectively (Vaska \& Volkmer, 2004).

Similar studies show children from low socio-economic groups have a greater risk of obesity than those who are more affluent families (Drewnowski, Drewnowski, \& Darmon, 2005; Lobstein, Baur, \& Uauy, 2004; O'Dea, 2003; Wang, 2002). A South Australian study of 4 year olds found that overweight and obesity rates were almost $4 \%$ higher among the lowest quintile or most disadvantaged children, compared with the highest quintile or least disadvantaged children (Tennant, Hetzel, \& Glover, 2003).

Equally concerning is the evidence of the sequela of the physical, emotional, and social problems associated with childhood obesity. Physical risks, such as, high blood pressure and abnormal blood lipids (Figueroa-Colon R, Franklin, \& Lee, 1997), diabetes (Freedman, Serdula, Srinivasan, \& Berenson, 1999), and asthma and respiratory problems (Leung, 1990) are being linked with childhood obesity. Paediatric overweight is also associated with overweight in adulthood (Guo \& Chumlea, 1999; Margarey, Daniels, \& Boulton, 2001; Whitaker, Wright, Pepe, Seidel, \& Dietz, 1997; Wisemandle, Maynard, Guo, \& Siervogel, 2000), where the risks of obesity are well-defined (Allison, Zannolli, \& Narayan, 1999; Must, Hollander, \& Economos, 1999). An international review estimates that about one-third of overweight preschool children and one-half of overweight school children remain overweight as adults (Serdula et al., 1993). While an Australian longitudinal study has shown that body mass index (BMI) at six years is a good indicator of adult BMI (Margarey et al., 2001). Thus the promotion of healthy lifestyles among young children and the prevention of childhood overweight may result in benefits, not only in terms of modifying health risks in children, but also in terms of lowering rates of chronic disease in adults.

In addition to physical health risks, a number of emotional and social problems are associated with overweight during childhood (Dietz, 1998; Janssen, Craig, Boyce, \& Pickett, 2004; Strauss, 2000) with evidence showing that children from 5 years of age can sense prejudice towards their obesity (Ebbeling, Pawlak, \& Ludwig, 2002). Children who are overweight are more likely to be negatively stigmatised than almost 
any other social group (Pesa, Syre, \& Jones, 2000; St-Onge, Keller, \& Heymsfield, 2003; Stradmeijer, Bosch, Koopsk, \& Seidell, 2000), are liked to a lesser extent or are rejected by peers (Bell \& Morgan, 2000; Goldfield, 1995; Maddox \& Liedermann, 1969; Strauss, 1984), and are more likely to experience peer aggression, such as teasing and bullying (Janssen et al., 2004; Pearce, Boergers, \& Prinstein, 2002; Slee \& Rigby 1993). Further links have also been drawn between overweight and obesity in children, negative body image (Buddeberg-Fischer, 1999; Manus \& Killeen, 1995), and low self-esteem (Ebbeling et al., 2002).

The direct financial burden of obesity alone in Australia was estimated to be $\$ 3.767$ billion in 2005 , including $\$ 873 \mathrm{~m}(23 \%)$ due to health system costs, while the indirect costs due to loss of well-being were valued at a further $\$ 17.2$ billion, bringing the total cost of obesity in 2005 to $\$ 21$ billion (Access Economics, 2006). With projections based on current levels and demographic trends indicating that by 2025 , a total of 4.2 million (16.7\%) Australians will be obese, and figures set to rise to 7.2 million (28.9\%) if current historic rates of increase continue (Access Economics, 2006), developing effective strategies for the primary prevention of overweight among preschool children is critical in order to enhance the development of healthy lifestyles from a young age and stem the obesity epidemic (Baranowski et al., 2000). Yet despite this, there remains a significant paucity of successful interventions for preschool children (Flynn, McNeil, Maloff, Wu et al., 2006; Hearn et al., 2006).

\section{Australia's Primary Health Care Policy Response: How Appropriate are Existing Frameworks?}

Australia was one of the first countries to produce an integrated strategy for the prevention of overweight and obesity. The report Acting on Australia's Weight: A Strategic Plan for the Prevention of Overweight and Obesity (National Health and Medical Research Council, 1997), drew on the work of Egger and Swinburn (1997), and proposed a shift away from the individually-focused strategies, towards a more population focused approach to obesity prevention involving environmental (physical, economic and socio-cultural), structural (legal, political and tax) and behavioural (attitudes, beliefs, habits, emotions, cognitions), changes. To date, the Government's efforts have mainly targeted the creation of supportive environments for the promotion of regular physical activity (Department of Health and Ageing, 2004a, 2004b; National Public Health Partnership, 2005) and healthy nutrition (National Health and Medical Research Council, 2003) in children. State governments have also developed a range of complementary policies and strategies and trialled a limited range of interventions particularly in the area of nutrition (Hearn et al, 2006).

To ensure 'the healthy growth of children', the Government and many nongovernment groups have placed particular emphasis on the school as a key setting for changing access to food choices and physical activities (Campbell, Waters, O'Meara, Kelly, \& Summerbell, 2005; Doak, Visscher, Renders, \& Seidell, 2006; Flynn, McNeil, Maloff, Mutasingwa et al., 2006). Yet the outcomes of these efforts are equivocal (Hearn et al., 2006), partly due to limited evaluation methodology (Resnicow \& Robinson, 1997; Thomas, 2006), as well as more serious theoretical and practical limitations (Birch, 2001). Moreover, the theoretical framework used in school-based interventions has tended to focus on the conventional model of health promotion that assumes changes in knowledge, supported by changes in infrastructure, will lead to changes in behaviour (Campbell \& Crawford, 2001; Egger \& Swinburn, 1997; O'Dea, 2003). 
Moreover, emphasis on school-based interventions does not adequately recognise that food preferences, and also to some extent the sedentary lifestyles, of children are generally be well-established by the time they reach school age (Birch, 1999; Burke, Beilin, \& Dunbar, 2001). Birch (1999) argues that early exposure to fruits and vegetables, and to foods high in energy, sugar and fats, plays an important role in establishing a hierarchy of food preferences. Not surprisingly, therefore, a strong relationship has been found between the food preferences of toddlers and those of their families, with obese parents with preferences for high fat foods more likely to have overweight children with similar food preferences (Burke et al., 2001).

More recently emphasis has shifted towards a more contextual model of childhood obesity (Birch, 2001; Thomas, 2006) based on ecological systems theory (Bronfenbrenner, 1989), whereby preventative strategies focus beyond the child, on parents, families, communities, and particularly primary care services and providers. In accordance with this thinking, the Australian Government's recent national frameworks - 'Healthy Weight 2008 - Australia's Future: The National Agenda for Young People and their Families', 'The National Agenda on Early Childhood', and Healthy Children - Strengthening Promotion and Prevention across Australia' - have specifically targeted strengthening the role of parents, communities, teachers, child care workers and primary health care providers. Nevertheless to be effective, such a process will require a paradigm shift away from merely focusing on "what" are some of the causal pathways leading to overweight and obesity in young children and how these can be addressed, towards focusing on "who" are the key primary health care providers of young children and "how" can best be engaged in the process (Gill, King, \& Webb, 2005; Kumanyika, 2005; Tremblay, 2003).

\section{Reviewing the Evidence for Informed Decisions}

Given that up to the age of 4 years, primary health care providers generally have more regular contact with children and their parents (Gunner, Atkinson, Nichols, \& Eissa, 2005; Lobstein et al., 2004; O'Brien, Holubkov, \& Reis, 2004; Sohn, Ismail, \& Tellez, 2004), they are in an influential position to monitor and modify factors that contribute to unhealthy weight gain to ensure early intervention. However, currently a variety of systems level, attitudinal and behavioural, and knowledge, skills and training barriers appear to prevent their effective engagement with parents and other child care providers (Hearn et al, 2006). Yet if strengthening the role of primary health care providers (PHCPs) is to remain a key strategy in the Government's efforts to promote healthy weight among young children, then policy makers and practitioners will require evidence-based summaries of research on what helps and/or hinders their engagement, as well as practical information on key characteristics of successful and/or promising interventions.

This paper presents the findings of a recent multi-method, systematic review focusing on the prevention of overweight and obesity among young children aged 2-6 years (Hearn et al., 2006), that had as its key objectives to:

- Identify the most appropriate PHCPs for mobilising change within families and other child care settings to promote healthy lifestyles among this age group, as well as the key barriers and enablers to engaging them in interventions for the prevention of overweight and obesity; 
- Appraise successful and/or promising interventions for strengthening the capacity of PHCPs to engage parents and child care staff in the promotion of healthy weight among young children aged $2-6$ years;

- Synthesise key policy options to address the barriers and facilitate the engagement of PHCPs in the promotion of healthy weight among young children in different settings based environments (clinical, child care, home and community).

The methodology used for the systematic review was based on the multi-method approach of Mays and others (2005).

\section{Understanding the Barriers to Primary Health Care Engagement}

For the purpose of this study, PHCPs were taken to include GPs, registered practice nurses, child health nurses, paediatricians, nutritionists, and allied health care providers. To date, their role has generally fallen within the category of the 'individually oriented treatment of obesity' (Gill, King, \& Caterson, 2005; Gill, King, \& Webb, 2005; Kumanyika, 2005). However, nationally their role has been defined more broadly to include the promotion of well-being and disease prevention (Australian Health Ministers' Council, 1988), and hence there are growing calls for a re-orientation of their responsibilities to include more population focused and upstream tasks, encouraging PHCPs to play a more active role as educational, environmental and political protagonists facilitating lifestyle changes within families and other child care environments (Kumanyika, 2005). Achieving this will require the development of coordinated, multi-sector partnerships and interventions, directed at health care and child care centres, preschools, schools, and communities to strengthen the links between PHCPs, child care providers, communities and families - a process that necessitates a clear understanding of the barriers currently preventing PHCPs from working closely with parents and other setting based service providers.

Figure 1: $\quad$ Strengthening the Link between PHCPs, Settings, Parents and Families

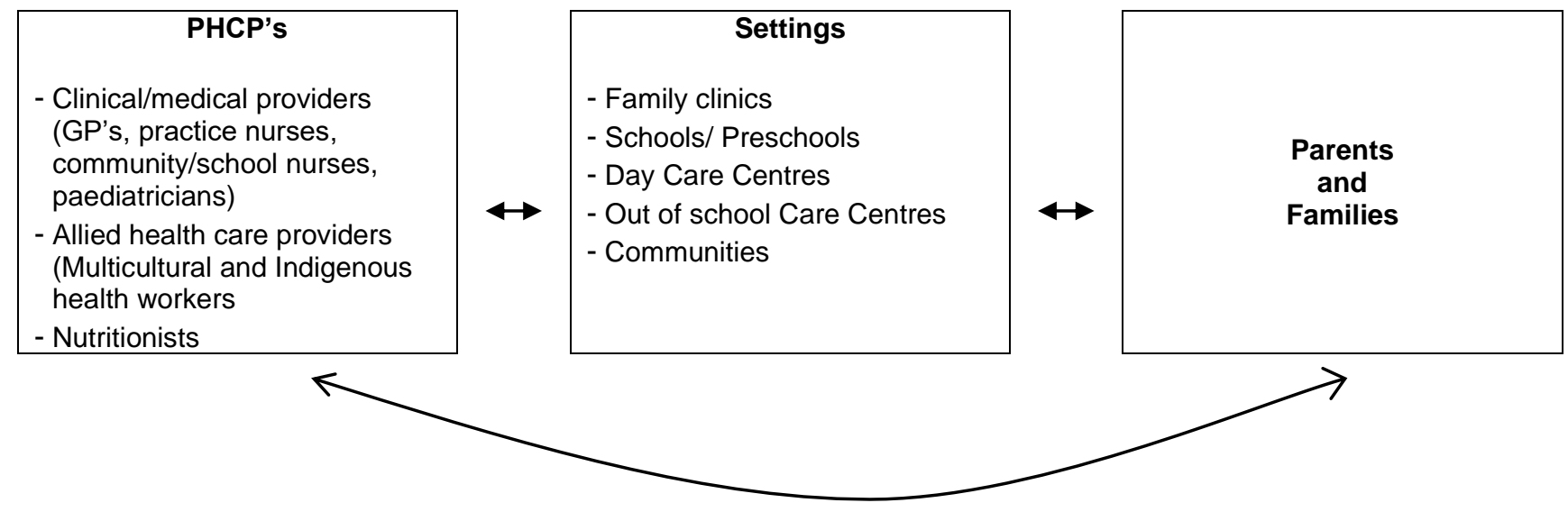


The review found that among all three of these categories, a series of systems level; attitudinal; knowledge, skills and training; lifestyle; research; and organisational barriers are presently hampering effective collaboration.

\section{Systems Level and Organisational Barriers}

Despite Australia introducing Clinical Guidelines for the Management of Overweight and Obesity in Children and Adolescents in 2003, which recommended bi-annual monitoring of all children for detecting and preventing overweight, less than a quarter of PHCPs reported following these guidelines (Gunner et al., 2005). One of the major barriers identified for their implementation has been lack of time and reinforcement (Dietz \& Nelson, 1999; Sallis et al., 2000). Typically, PHCPs and especially general practitioners, have a limited time with their patients and this is intensified by financial pressures to maximize productivity (Helman, 1997; Jelalian, Boergers, Alday, \& Frank, 2003; Mercer \& Tessier, 2001). Thus, as prevention of weight gain is rarely perceived as their core business, it is given low priority in the face of competing demands. Not only does public health insurance not cover this cost, but Tershakovec et al.(Tershakovec, Watson, Wenner, \& Marx, 1999) found an average reimbursement rate of only $11 \%$ across insurance providers, with level of reimbursement not associated with degree of risk, and with some children with medical consequences being denied support. Thus while primary health care providers do see children frequently up until the age of 4 years, unless insurance and managed care policies change, health care professionals will have little incentive to provide childhood obesity prevention services.

Lack of resources is also cited as a key limitation, with opportunities for preventative counselling in the health care setting being limited by lack of office support staff (practice nurses, etc) or systems for follow up interventions after GP visits, lack of availability of appropriate patient educational materials, and the limited number of specialists to whom referrals can be made (Sallis et al., 2000). Moreover, difference in socio-economic status affects access to health care services, with children from lower income families less likely to receive preventative care than those from higher income families (Newacheck, Stoddard, Hughes, \& Pearl, 1998), despite being at greater risk of overweight.

Furthermore, although the broader definition of PHCPs incorporates a variety of allied health care providers from both the government and non-government sectors, and calls for greater collaboration with other child care providers, such as child care centres and pre/primary schools, these groups come under the supervision of different government departments (Department of Family and Community Services, Department of Education, Science and Training, and Department of Health), some of which are funded at the local or state level rather than national level, making coordination of strategies difficult to implement (VicHealth, 2003).

\section{Attitudinal and Communication Barriers}

In addition to these systems level problems, PHCPs have also cited parents' attitudinal barriers and lack of interest as a key factor both preventing their initial engagement with parents and facilitating their ongoing involvement in interventions. A significant proportion (70\%) of mothers with overweight or obese children do not perceive their children overweight, and do not report being concerned about their preschool children's weight (Campbell, Williams, Hampton, \& Wake, 2006)., and 
prefer to describe them as big-boned, thick-set, sweet-toothed or with a predisposition to be large (Baughcum, Chamberlin, Deeks, Powers, \& Whitaker, 2000; Carnell, Edwards, Croker, Boniface, \& Wardle, 2005; Jeffery, Voss, Metcalf, Alba, \& Wilkin, 2005; Maynard, Galuska, Blanck, \& Serdula, 2003; Wake, Salmon, Waters, Wright, \& Hesketh, 2002a). Further, increasing prevalence of overweight in young children and the media's portrayal of extreme stereotypes have distorted lay perception of overweight (Campbell et al., 2006).

Parental obesity is one of the strongest predictors of childhood obesity (American Academy of Pediatrics, 2003; Danielzik, Czerwinski-Mast, Langnase, Dilba, \& MÃller, 2004; Epstein, 1996; Strauss, 1999). Whilst there is a small genetic component (Stunkard, Foch, \& Hrubec, 1986) most is related to lifestyle with children following the lifestyle examples of their parents and families (Golan \& Crow, 2004; Strauss, 2002; Wardle, Guthrie, Sanderson, Birch, \& Plomin, 2001). Research indicates that if both parents are obese, there is a $70 \%$ chance that their children will be obese; if one parent is obese, there is a $50 \%$ chance that their children will be obese; and if neither parents are obese there is only a $10 \%$ chance their children will be obese (Epstein, 1996; Klish, 1995; Slyper, 1998).

This role modelling has served to exacerbate the already negative views held by many health professionals not only towards obesity as a condition, but also towards obese people. Health professionals typically associate overweight with overindulgence, laziness, poor hygiene, and even hostility (Klein, 1982; Maroney, 1992; Schwartz, ONeal, Brownell, Blair, \& Billington, 2003; Teachman \& Brownell, 2001; Teachman, 2001), with GPs tending to blame both the cause and the solution to the problem on the patient and their inability to control personal factors, rather than on a combination of individual and environmental factors (Ogden et al., 2001), and hence believe the responsibility lies primarily with the patient (2001). In contrast, parents have placed greater emphasis on environmental rather than individual factors, and have expressed difficulty establishing and maintaining healthy eating habits for children when confronted with limited time if they both work, their children's endless appetites, or when their children's diets is challenged by family, friends, and the media (Jain et al., 2001; McKey \& Huntington, 2004). Moreover, many parents consider providing ample nourishment to their children to be an important and emotionally rewarding part of parenting that they were unwilling to relinquish (Jain et al., 2001).

Other studies have drawn attention to the communication barriers between PHCPs, and parents, indicating that mothers are sceptical about health professionals classification of their children as overweight based on height and weight charts, and BMI (Eckstein et al., 2006; Jain et al., 2001) and that informing parents of their child's $\mathrm{BMI}$ and the risks of overweight alone are rarely sufficient to bring about behavioural change (Rollnick, Butler, McCambridge, Kinnersley, \& Elwyn, 2005). But, while mothers did not appear concerned about BMI, many acknowledged that they would become concerned if they felt their child were becoming inactive, or were being teased by peers as a result of their weight (Jain et al., 2001; Janssen et al., 2004). For mothers, low self-esteem, bullying, and inactivity were the most critical factors affecting whether they would become worried and seek support to change their child's lifestyle patterns. Thus improved understanding of how parents make sense of the causes and consequences of being overweight, could greatly enhance PHCPs models of communication and methods of treatment (Ogden et al., 2001). 
Despite extensive research on the negative attitudes of many PHCPs, and particularly GPs, towards involvement in interventions for the promotion of healthy weight, few such studies have focused specifically on childhood obesity (Price, Desmond, Krol, Snyder, \& O'Connell, 1987; Story et al., 2002). A recent Australian study of paediatricians, paediatric nurse practitioners, and registered dieticians, however, showed far more positive attitudes towards managing childhood obesity (Story et al., 2002). In all three professional groups, respondents felt that childhood overweight was a condition that needs treatment (75-93\%), as it affects children's quality of life (83-93\%) and increases their risk of chronic disease (76-89\%). Moreover, nearly half the PHCPs questioned felt that the prevention and management of childhood overweight was more amenable than that of adult overweight. Nevertheless, only a quarter of PHCPs working with children felt competent in the use of parental guidance techniques, behaviour management strategies, and methods for addressing family conflicts in dealing with paediatric obesity (Gerner, McCallum, Sheehan, Harris, \& Wake, 2006; Jelalian et al., 2003; Story et al., 2002), and few reported any confidence in their ability to change patient behaviour (Kushner, 1995).

Currently, PHCPs have few opportunities to strengthen their counselling and behavioural management techniques for childhood obesity, as these topics are rarely covered in medical, nursing, or dietetic school curricula, and there are few opportunities for postgraduate training (World Health Organization, 1997). Nevertheless, paediatric practitioners and health care providers report a high level of interest in training to improve their skills in assessing and monitoring weight, and in the early prevention and treatment of obesity, including guidance and parenting techniques (Story et al., 2002). In particular, there is a growing interest to develop skills in behavioural management and in guidance in parenting techniques, with almost a half expressing interest in further training and on-going education in these areas. A high level of interest among PHCPs has also been identified in promising new techniques such as stages of change counselling, motivational interviewing, negotiation, behavioural self management, and tailored messages (Davis et al., 2006; Miller \& Rollnick, 1991; Prochaska \& DiClemente, 1986; Prochaska, DiClemente, \& Norcross, 1992; Resnicow et al., 2001), with some approaches having already been simplified and used with patients in clinical settings (Berg-Smith et al., 1999; Campbell, 1994).

In the US, practice nurses, in particular, report greater experience in working with parents than family nurse practitioners, and are more likely to encourage parents to offer nutritious snacks, model healthy food choices, allow their children to selfregulate meal intake, and promote physical activity (Larsen, Mandleco, Williams, \& Tiedeman, 2006). This has important policy implications as practice nurses in the US receive more training for children's health than family nurse practitioners. A final barrier for nurses is the lack of resource, educational materials and handouts to reinforce patient teaching and to supplement their own knowledge and for patient teaching (Larsen et al., 2006).

Thus increased knowledge and training among health care professionals may significantly reduce negative attitudes and stereotypes about obesity among medical students, and may promote greater empathy and interest on the part of PHCPs to work with parents and children to address the problem (Hankey, Eley, Leslie, Hunter, \& Lean, 2004; Harvey, Glenny, Kirk, \& Summerbell, 2001; Wiesemann, 1997). Nevertheless, while positive trends are emerging regarding PHCPs attitudes towards the prevention of childhood obesity, a large shift in their present approach 
emphasising treatment rather than lifestyle education and advocacy is unlikely to occur without a significant investment to improve their knowledge, skills and technical ability to translate their growing interests into practice. 
Table 1: Summary of Barriers to Parent and Primary Health Care Provider Participation

\section{Barriers to Primary Health Care Provider Involvement} System level barriers

- Prevention of overweight not perceived as core business of PHCPS

- Time pressures on PHCPs, and in particular on GPs

- Lack of support staff and systems for follow-up

- Lack of resources or opportunities for preventative counselling

- Lack of referrals to specialists due to concern for patient compensation

- Too much emphasis on treatment rather than prevention

- Lack of time to participate in group training and counselling sessions

Lack of appropriate support materials

\section{Attitudinal/Lifestyle Barriers}

- Negative 'victim blaming' attitudes towards overweight people

- Lack of response from parents who feel PHCPs are negative/dismissive

- Fear of parents becoming sensitive to comments

- Feel uncomfortable dealing with issues of overweight

- PHCPs can be poor role models which adds to their feeling of discomfort in dealing with issues of overweight

\section{Knowledge, Skills and Training Barriers}

- Lack of knowledge/understanding of lifestyle/environmental factors affecting weight

- Low skill proficiency and lack of training in use of behaviour management strategies

- Lack of knowledge in parental guidance techniques or how to address family conflicts

- Lack of educational resources to supplement their own knowledge

- Dislike of existing clinical guidelines and materials for use with parents

\section{Research Barriers}

- Lack of rigorously evaluated studies on the effectiveness of different interventions

\section{Organisational/ Coordination Barriers}

- Nature of general practice is disparate, and there are limited tools for reaching and influencing independent practices

- Limited collaboration between outreach clinics with designated PHC specialists, and other allied health care providers and professionals working in child care and community settings

\section{Barriers to Parent Participation}

\section{System level barriers}

- Norms of different socio-economic and cultural groups affect willingness and ability of parents to comply with healthy lifestyles

- Families living in isolated or poorly serviced neighbourhoods, may not have easy access to healthy foods, or safe areas for children to physically active

- Fruit, vegetables and other healthy foods are often more expensive than less healthy foods and snacks

\section{Attitudinal/Lifestyle Barriers}

- Parents are frequently poor role models with regards diet and physical activity

- Parents often do not perceive their children as overweight and are sceptical about BMI and height/weight charts

- Stereotypes in the media focus on extreme examples of obesity reducing the importance of dealing with early signs of overweight

- Parents can misinterpret overweight children as 'healthy' eaters and by exerting strong control of quantities of food eaten, do not allow children to learn skills in self-regulation

- Parents work and lifestyles limits time available to structure eating habits or prepare nutritious meals

- Parents often feel powerless in light of commercial advertising, and challenges from grandparents, friends, etc.

- Parents are more likely to take action if they perceive their children are suffering psychologically due to poor self-esteem or bullying

\section{Knowledge, Skills and Training Barriers}

- Parents often receive conflicting messages regarding what is healthy

- Too much of the information provided emphasises 'what' to do rather than assisting parents/communities in 'how' to achieve it

- Information is often too general and not targeted to specific needs of different population groups

- Information and training often fails to take account of family conflicts in dealing with key issues around food, TV watching, etc. 


\section{Reducing the Barriers to Primary Health Care Engagement - Lessons from Promising Interventions}

In light of these barriers, a systematic literature review was conducted to identify and synthesise the findings of successful and/or promising interventions to engage PHCPs in efforts to empower parents and child care providers to play an active role in the promotion of healthy weight among children aged 2-6 years (Hearn et al, 2006). Despite initially collating information on some 982 interventions, only 45 of these interventions were aimed specifically at children age 2-6 years, and met our other inclusion criteria of: being primarily focused on prevention and early intervention; involving primary health care providers as key facilitators of change; encouraging the participation of parents and other family members; detailing the methodology used to evaluate, research, and/or review the intervention's outcomes, process, and acceptability; and being implemented since 1990.

Borrowing on the research methodology of Flynn and colleagues (Flynn, McNeil, Maloff, Wu et al., 2006; Flynn, McNeil, Maloff, Mutasingwa et al., 2006), a secondary appraisal was completed to rate the 45 interventions according to their:

- methodological rigour;

- program impact and transferability;

- capacity to engage primary health care providers;

- capacity to enhance parental participation;

- ability to encourage primary health care providers to adopt a more population based approach focusing not merely on individual but incorporating the family, community and broader environment;

- ability to shift the role of primary health care providers from emphasis on treatment towards prevention through involvement in more upstream activities (education, environmental policy and advocacy); and

- capacity to encourage parents and primary health care providers to deal with the complex, multi-dimensional risk factors associated with overweight and obesity in young children.

Based on this secondary appraisal, 11 interventions were assessed to show significant 'promise' for achieving at least two of the key criteria (Table 2). These 11 interventions were described in detail and their potential policy implications for different clinical, child care, and home and community based settings were summarised (Hearn et al., 2006).

Table 2: Promising Interventions

\begin{tabular}{|l|l|l|}
\hline INTERVENTIONS & PHCP & COUNTRY \\
\hline Clinical & Nutritionists, Nutrition Assistants & US \\
\hline Fit WIC (Herzog, 2005) & US \\
\hline $\begin{array}{l}\text { Nutrition Aimed at Toddlers: An Intervention } \\
\text { Study (NEAT) (Horodynski \& Stommel, 2005) }\end{array}$ & $\begin{array}{l}\text { Nutritionists, trained } \\
\text { paraprofessional nutrition } \\
\text { instructors }\end{array}$ & US \\
\hline $\begin{array}{l}\text { Special Turku Coronary Risk Factor Intervention } \\
\text { Project (Gable \& Lutz, 2001; Koblinsky, Guthrie, } \\
\text { \& Lynch, 1992) }\end{array}$ & $\begin{array}{l}\text { Multidisciplinary health team (Dr, } \\
\text { Dietician, Registered Nurse) }\end{array}$ & \\
\hline $\begin{array}{l}\text { Child care and pre-school } \\
\text { Lewis, \&ight - Eat Right award scheme (Pollard, }\end{array}$ & $\begin{array}{l}\text { Allied Health Professionals \& Child } \\
\text { Care staff }\end{array}$ & Aus \\
\hline $\begin{array}{l}\text { Good Food for Children (Bravo \& Cass, 2003; } \\
\text { Sangster, Chopra, \& Eccleston, 1998; Sangster, } \\
\text { Eccleston, \& Stickney, 2003) }\end{array}$ & $\begin{array}{l}\text { Allied Health Professionals, Child } \\
\text { Care staff, Parents/Carers }\end{array}$ & Aus \\
\hline
\end{tabular}




\begin{tabular}{|l|l|l|}
\hline $\begin{array}{l}\text { Sharing a picture of children's development } \\
\text { (Centre for Community Child Health; Royal } \\
\begin{array}{l}\text { Children's Hospital; Australian Dairy Council, } \\
\text { 2005) }\end{array}\end{array}$ & Multi-professional & Aus \\
\hline Caring for Children (Bunney \& Williams, 2005) & $\begin{array}{l}\text { Child care staff, allied health } \\
\text { workers and parents }\end{array}$ & Aus \\
\hline $\begin{array}{l}\text { Hip-Hop to Health Jr (Fitzgibbon, Stolley, Dyer, } \\
\text { VanHorn, \& KauferChristoffel, 2002; Fitzgibbon } \\
\text { et al., 2005; Stolley et al., 2003) }\end{array}$ & Child Care staff \& parents & US \\
\hline Home and community & & \\
\hline Family Food Patch (Eat Well Tasmania, 2006) & Dieticians \& parent volunteers & Aus \\
\hline $\begin{array}{l}\text { Be Active, Eat Well: Making it Easy (Deakin } \\
\text { University) }\end{array}$ & $\begin{array}{l}\text { Multidisciplinary (Dieticians \& GPs, } \\
\text { parents/carers) }\end{array}$ & Aus \\
\hline $\begin{array}{l}\text { Growth Assessment and Action Program } \\
\text { (Northern Area Health Service, n.d.) }\end{array}$ & Aboriginal Health Care workers & Aus \\
\hline
\end{tabular}

The key lessons that can be drawn from these promising interventions are:

- In clinical settings, there is a need to build a culture among PHCPs and parents of prevention rather than management, and a change of focus from weight to healthy lifestyle. This could be achieved either through an expansion of the mother baby clinics available universally across Australia, or through the setting up of similar systems in GP and outreach clinics to register, store and monitor data with reminder systems, and smarter database tools other than BMI for early recognition of at risk children. There is a need also for improved training packages to better equip staff in the provision of parental guidance, counselling, and support systems to overcome barriers for parents attempting to implement changes. The implementation of these approaches would require extensive consultation between parent and PHCPs.

- In childcare and early childhood education settings, staff need a better understanding of the importance of the early development of food preferences, eating habits and physical activity in shaping healthy lifestyles during later years, and of their role in achieving this. Currently, the importance of good nutrition is recognised in many childcare programs, but there is need to increase emphasis on active play and development of fundamental movement skills in pre-school children. The most efficient method to effect universal implementation of good practice in promoting healthy lifestyles in childcare centres is to introduce minimum standards for relevant components in childcare licensing agreements, supported by staff training. Quality improvement award schemes can also be effective in the absence of licensing requirements. While the review identified several effective approaches to staff development in nutrition and food service, the provision of training to childcare staff is problematic due to staff rostering issues, lack of financial and career path incentives to invest personal time in training, and high staff turnover. However, standards and training materials have been developed by health professionals, and there is need now for ongoing input to revise these and establish stronger partnerships between child care centres, parents and PHCPs to reinforce the important impact that childcare practices can have on development of healthy lifestyles for prevention of overweight.

- In home and community settings, parents need information and supportive environments to help them deal with issues such as negotiating dietary change, setting limits on television, and unhealthy influences of family, friends, and media. Research into sources of nutrition knowledge repeatedly shows that health professional, friends and family are the most significant source of nutrition and health information for parents, particularly those with low education levels. PHCPs providing training and empowering parents to become peer educators and advocates for healthy lifestyles in their own communities has the immediate 
intended benefits of development of local solutions to local problems, and delivery of salient messages to potentially hard-to-reach groups by a low cost volunteer workforce. Translating this concept to the early childhood target group, suggests recruitment of volunteer parents to work with primary health care services, community service organisation and child-care settings.

- To play a more active role as educational, environmental and political protagonists facilitating lifestyle changes within families and other child care environments, PHCPs will require specific training. The nature of training and best modes of delivery need to be explored with relevant PHCPs. At a preservice training level, universities need to review undergraduate and postgraduate curricula for GPs, nurses, dieticians and other allied health care providers, with the goal of introducing topics relating to stages of change counselling, motivational interviewing, negotiation, behavioural self management, parental guidance and conflict management, as well as environmental change theory so that PHCPs feel more comfortable dealing with parents and have a greater understanding of the broaden aspects affecting the uptake of preventative health care. In-service professional development courses for GPs and nurses on how to integrate non-threatening family and lifestyle counselling into routine primary and secondary care could also prove productive. While short-term university and TAFE courses for child care workers, and particularly potential directors of child care centres or principals of preschools/schools, need to be developed to provide training in policy planning on key aspects relating to: nutrition and physical activity planning; communication frameworks for enhancing parent participation; networking and support; and curriculum development to enhance healthy lifestyles. In addition, PHCPs across all settings, should have access to staff wellness programs to enhance their self-esteem and to encourage them to become role models promoting healthy lifestyles to children and parents. Moreover, this needs to be supported through increased funding for the production and dissemination of education materials, developed with greater participation from PHCPs and child care providers.

- At the research level, there is a need for funding bodies to provide support for high quality research to evaluate the effectiveness, impact, and outcomes of different interventions for engaging parents through PHCPs. Furthermore, to ensure best use of scarce health resources, a clearer understanding of the costeffectiveness of different approaches is desirable.

\section{Methodological Issues}

While the review involved a systematic and extensive search of 14 black literature databases, 10 grey literature databases, internet searches, hand searches of government and peak body policy papers, bibliographies of published and unpublished materials, as well as consultations with key stakeholders and experts in the field, there were a number of limitations to this study. First, was the lack of practical interventions that addressed primary prevention and early intervention for children aged 2-6 years, and that involved both primary health care providers and parents. Second, was the lack of information provided in the literature on the methodologies used to assess the effectiveness of the interventions, as well as the lack of methodological rigour in analysing research findings (irrespective of whether these were based on quantitative RCTs or qualitative research techniques). In most cases, there were limited population level data, small sample sizes, and lack of longitudinal data showing sustained change. Third, was the use of varying outcome measures that made comparisons between interventions difficult. Moreover the 
limited evidence available tended to focus on individual knowledge or attitudinal change, rather than behavioural and environmental change, while additionally there was a shortage of data showing the influence of socio-economic, cultural, and gender factors on the effectiveness of different approaches. Four, was the lack of process level data on the interventions' effectiveness in terms of their replicability, political feasibility, community acceptability, service delivery and capacity building needs.

In light of these limitations, while the study sheds light on some potentially promising interventions for encouraging and engaging primary health care providers and parents in the prevention of overweight and obesity, further research is required to determine their effectiveness for both the general population and specific target groups.

\section{Future Directions}

Nevertheless, what the study has aimed to demonstrate is that any effort to stem Australia's growing obesity epidemic will require strengthening the capacity of parents and other child care providers to promote healthy weight among children aged 2-6 years, prior to the onset of poor eating habits and sedentary behaviours. While school based interventions are clearly important, there appears to be a critical gap in research and interventions aimed at primary prevention among this younger age group, and as a consequence Australia is witnessing rising levels of overweight and obesity among preschool children that are likely to have a significant long term social, emotional and economic impact. Moreover, with growing consensus indicating that addressing this gap will require a more contextual model of childhood obesity based on ecological systems theory, aimed specifically at strengthening the role of primary health care providers to engage with parents, communities, teachers, and child care workers, there it is urgent need to refocus our efforts towards identifying: a) who are the best primary health care providers to implement such changes; b) what are the most effective means of engaging them; c) what support mechanisms are required to sustain their engagement; and d) how can these best be targeted to different socio-economic and cultural groups.

\section{Acknowledgements}

This paper is the outcome of a project funded by the Australian Primary Health Care Research Institute, supported by a grant from the Australian Government Department of Health and Ageing. While the information and opinions do not necessarily reflect their views, we gratefully acknowledge the contribution made by the managers and policy makers of these organisations who acted as discussants. We would also like to acknowledge the direction and guidance provided by Professor Ken Resnicow, Dr. Delia Hendrie, and Ms. Sue McHutchison. Thanks too to the librarians, and all the members of the Child Health Promotion Research Centre who participated in the project, and especially to the continuous and dedicated support of Renee CampbellPope. 


\section{References}

Access Economics. (2006, October). The economic costs of obesity. Retrieved December 10,2006 , from

http://www.accesseconomics.com.au/publicationsreports/showreport.php?id=102

Allison, D. B., Zannolli, R., \& Narayan, K. M. V. (1999). The direct health care costs of obesity in the united states. American Journal of Public Health, 89(8), 1194-1199.

American Academy of Pediatrics. (2003). Prevention of pediatric overweight and obesity. Pediatrics, 112(2), 424-430.

Australian Bureau of Statistics. (1995). National nutrition survey: Nutrient intakes and physical measurements, Australia. Retrieved December 18, 2005, from AusStats database.

Australian Health Ministers' Council. (1988). Health for all Australians. Summary of the report to the Australian health ministers'. Health Promotion International, 3, 219-236.

Australian Institute of Health and Welfare. (2003). Australia's young people: Their health and wellbeing 2003 (AlHW Cat No. PHE50; ABS Cat No. 8922.0). Canberra: AIHW.

Baranowski, T., Mendlein, J., Resnicow, K., Frank, E., Cullen, K. W., \& Baranowski, J. (2000). Physical activity and nutrition in children and youth: An overview of obesity prevention. Preventive Medicine, 31(Suppl. 2), 1-10.

Baughcum, A. E., Chamberlin, L. A., Deeks, C. M., Powers, S. W., \& Whitaker, R. C. (2000). Maternal perceptions of overweight preschool children. Pediatrics., 106(6), 13801386.

Bell, S. K., \& Morgan, S. B. (2000). Children's attitudes and behavioral intentions toward a peer presented as obese: Does a medical explanation for obesity make a difference? Journal of Pediatric Psychology, 25(3), 137-145.

Berg-Smith, S. M., Stevens, V. J., Brown, K. M., Van Horn, L., Gernhofer, N., Peters, E., et al. (1999). A brief motivational intervention to improve dietary adherence in adolescents. Health Education Research, 14(3), 399-410.

Birch, L., Davidson, K.K. (2001). Family environmental factors influencing the developing behavioral controls of food intake and childhood overweight. Pediatric Clinics of North America, 48, 893-907.

Birch, L. L. (1999). Development of food preferences. Annual Review of Nutrition, 19, 41-62.

Bravo, A., \& Cass, Y. (2003). Good food in family day care-improving nutrition and food safety in family day care schemes: Implementation and evaluation report. Sydney, NSW: Health Promotion Service.

Bronfenbrenner, U. (1989). Ecological systems theory. Annals of Child Development, 6, 187249.

Buddeberg-Fischer, B., Klaghofer, R, Reed, V. (1999). Associations between body weight, psychiatric disorders and body image in female adolescents. Psychotherapy and Psychosomatics, 68, 325-332. 
Bunney, C., \& Williams, L. (Eds.). (2005). Caring for children: Food, nutrition and fun activities (4 ed.). Sydney: NSW Health.

Burke, V., Beilin, L. J., \& Dunbar, D. L. (2001). Family lifestyle and parental body mass index as predictors of body mass index in Australian children: A longitudinal study. International Journal of Obesity, 25, 147-157.

Campbell, K., \& Crawford, D. (2001). Family food environments as determinants of preschool-aged children's eating behaviours: Implications for obesity prevention policy. A review. Australian Journal of Nutrition and Dietetics, 58(1), 19-25.

Campbell, K., Waters, E., O'Meara, S., Kelly, S., \& Summerbell, C. (2005, July 20). Interventions for preventing obesity in children. Cochrane Database of Systematic Reviews, 2005(3), Art. No. CD001871. Retrieved November 18, 2005, from The Cochrane Library Database.

Campbell, M. K., DeVellis, B. M., Strecher, V., Ammerman, A., DeVellis, R. F., \& Sandler, B. (1994). Improving dietary behavior: The effectiveness of tailored messages in primary care settings. American Journal of Public Health, 84(5), 783-787.

Campbell, M. W.-C., Williams, J., Hampton, A., \& Wake, M. (2006). Maternal concern and perceptions of overweight in Australian preschool-aged children. Medical Journal of Australia, 184(6), 274-277.

Carnell, S., Edwards, C., Croker, H., Boniface, D., \& Wardle, J. (2005). Parental perceptions of overweight in 3-5 y olds. International Journal of Obesity, 29(4), 353-355.

Centre for Community Child Health; Royal Children's Hospital; Australian Dairy Council. (2005). Sharing a picture of children's development. Retrieved November 25, 2005, from http://www.rch.org.au/ccch/pub/index.cfm?doc id=936

Commonwealth of Australia. (2005). Building a healthy, active Australia: Why we need to act [fact sheet]. Retrieved March 02, 2005, from

http://www.facs.gov.au/Internet/facsinternet.nsf/via/early childhood/\$File/early childh ood-20feb03.pdf

Danielzik, S., Czerwinski-Mast, M., Langnase, K., Dilba, B., \& Maller, M. J. (2004). Parental overweight, socioeconomic status and high birth weight are the major determinants of overweight and obesity in 5-7y-old children: Baseline data of the Kiel Obesity Prevention Study (kops). International Journal of Obesity, 28(11), 1494-1502.

Davis, M., Gance-Cleveland, S., Hassink, S., Johnson, R., Paradis, G., \& Resnicow, K. (2006). Prevention of childhood obesity [revision 1.1], APHCRI Workshop. Perth: Institute of Medicine.

Deakin University. (n.d.). Be active, eat well communication plan. Retrieved November 28, 2005, from http://www.goforyourlife.vic.gov.au/hav/admin.nsf/Images/Communication Plan.pdf/\$ File/Communication Plan.pdf

Department of Family and Community Services. (2005). FACS longitudinal research updates. FaCSIA Research News(23), 8-10.

Department of Health and Ageing. (2004a). Australia's physical activity recommendations for 5-12 year olds. Canberra: Commonwealth of Australia. 
Department of Health and Ageing. (2004b). Australia's physical activity recommendations for 12-18 year olds. Canberra: Commonwealth of Australia.

Dietz, W. H. (1998). Health consequences of obesity in youth: Childhood predictors of adult disease. Pediatrics, 101(3), 518-525.

Dietz, W. H., \& Nelson, A. (1999). Barriers to the treatment of childhood obesity: A call to action. Pediatrics, 134(5), 535-536.

Doak, C. M., Visscher, T. L. S., Renders, C. M., \& Seidell, J. C. (2006). The prevention of overweight and obesity in children and adolescents: A review of interventions and programmes. Obesity Reviews, 7(1), 111-136.

Drewnowski, A. \& Darmon, N. (2005). The economics of obesity: Dietary energy density and energy cost. Science-based solutions to obesity: What are the roles of academia, government, industry, and health care? American Journal of Clinical Nutrition, 82(Suppl. 1), 265-273.

Eat Well Tasmania. (2006). Family food patch. Retrieved December 04, 2005, from http://www.eatwelltas.com.au/foodpatch.php

Ebbeling, C. B., Pawlak, D. B., \& Ludwig, D. S. (2002). Childhood obesity: Public-health crisis, common sense cure. The Lancet, 360(9331), 473.

Eckstein, K. C., Mikhail, L. M., Ariza, A. J., Thomson, J. S., Millard, S. C., Binns, H. J. (2006). Parents' perceptions of their child's weight and health. Pediatrics, 117(3), 681-690.

Egger, G., \& Swinburn, B. (1997). An "Ecological" Approach to the obesity pandemic. British Medical Journal, 315(7106), 477-480.

Epstein, L. H., Coleman, K.J., Myers, M.D. (1996). Exercise in treating obesity in children and adolescents. Medicine and Science in Sports and Exercise, 28, 428-435.

Figueroa-Colon R, Franklin, F., \& Lee, J., Aldridge, B., Alexander, L. (1997). Prevalence of obesity with increased blood pressure in elementary school-aged children. Southern Medical Journal, 90, 806-813.

Fitzgibbon, M. L., Stolley, M. R., Dyer, A. R., VanHorn, L., \& KauferChristoffel, K. (2002). A community-based obesity prevention program for minority children: Rationale and study design for Hip-Hop to Health Jr. Preventive Medicine, 34(2), 289-297.

Fitzgibbon, M. L., Stolley, M. R., Schiffer, L., Van Horn, L., KauferChristoffel, K., \& Dyer, A. (2005). Two-year follow-up results for Hip-Hop to Health Jr: A randomized controlled trial for overweight prevention in preschool minority children. Journal of Pediatrics, 146(5), 618-625.

Flynn, M., McNeil, D., Maloff, B., Wu, M., Mutasingwa, D., Ford, C., et al. (2006). Reducing obesity and related chronic disease risk in children and youth: A synthesis of evidence with 'best practice'recommendations. Obesity Reviews, 7(Web Suppl. 1), 199.

Flynn, M. A. T., McNeil, D. A., Maloff, B., Mutasingwa, D., Wu, M., Ford, C., et al. (2006). Reducing obesity and related chronic disease risk in children and youth: A synthesis 
of evidence with 'best practice' recommendations. Obesity Reviews, 7(Suppl. 1), 766.

Freedman, S., Serdula, M., Srinivasan, S., \& Berenson, G. (1999). The relation of circumferences and skinfolds to levels of lipids and insulin: The Bogalusa Heart Study. American Journal of Clinical Nutrition, 69, 308-317.

Gable, S., \& Lutz, S. (2001). Nutrition socialization experiences of children in the head start program. Journal of the American Dietetic Association, 101(5), 572-577.

Gerner, B., McCallum, Z., Sheehan, J., Harris, C., \& Wake, M. (2006). Are general practitioners equipped to detect child overweight/obesity? Survey and audit. Journal of Paediatrics and Child Health, 42, 206-211.

Gill, T., King, L., \& Caterson, I. (2005). Obesity prevention: Necessary and possible. A structured approach for effective planning. Proceedings of the Nutrition Society, 64(2), 255-261.

Gill, T., King, L., \& Webb, K. (2005). Best options for promoting healthy weight and preventing weight gain in NSW. North Sydney: NSW Department of Health. Retrieved December 19, 2006, from http://www.cphn.biochem.usyd.edu.au/resources/FinalHealthyWeightreport160305.p df.

Golan, M., \& Crow, S. (2004). Parents are key players in the prevention and treatment of weight-related problems. Nutrition Reviews, 62(1), 39-51. Retrieved September 08, 2005, from MEDLINE database.

Goldfield, A., Chrisler, JC. (1995). Body stereotyping and stigmatization of obese persons by first graders. Perceptual and Motor Skills, 81, 909-910.

Goodman, S., Lewis, P. R., Dixon, A. J., \& Travers, C. A. (2002). Childhood obesity: Of growing urgency. Medical Journal of Australia, 176(8), 400-401.

Gunner, K. B., Atkinson, P. M., Nichols, J., \& Eissa, M. A. (2005). Health promotion strategies to encourage physical activity in infants, toddlers, and preschoolers. Journal of Pediatric Health Care, 19(4), 253-258.

Guo, S. S., \& Chumlea, W. C. (1999). Tracking of body mass index in children in relation to overweight in adulthood. American Journal of Clinical Nutrition, 70(Suppl. 1), 145148.

Hankey, C. R., Eley, S., Leslie, W. S., Hunter, C. M., \& Lean, M. E. J. (2004). Eating habits, beliefs, attitudes and knowledge among health professionals regarding the links between obesity, nutrition and health. Public Health Nutrition, 7(2), 337-343.

Harvey, E., Glenny, A.-M., Kirk, S., \& Summerbell, C. (2001). Improving health professionals' management and the organisation of care for overweight and obese people. Cochrane Database of Systematic Reviews, Article CD000984. Retrieved November 07, 2005, from The Cochrane Library Database.

Hearn, L., Miller, M., Campbell-Pope, R., \& Waters, S. (2006). Preventing overweight and obesity in young children: Synthesising evidence for management and policy making. Retrieved January 10, 2007, from http://www.anu.edu.au/aphcri/Domain/AdolescentChildHealth/index.php 
Helman, A. (1997). Nutrition and general practice: An Australian perspective. American Journal of Clinical Nutrition, 65(Suppl. 6), 1939-1942.

Herzog, E. (2005). Fit wic: Programs to prevent childhood overweight in your community final report. Retrieved March 02, 2006, from http://www.fns.usda.gov/oane/MENU/Published/WIC/FILES/fitwic.pdf

Horodynski, M., \& Stommel, M. (2005). Nutrition aimed at toddlers: An intervention study (NEAT). Pediatric Nursing, 31(5), 364- 371.

Jain, A., Sherman, S. N., Chamberlin, L. A., Carter, Y., Powers, S. W., \& Whitaker, R. C. (2001). Why don't low-income mothers worry about their preschoolers being overweight? Pediatrics, 107(5), 1138-1146.

Janssen, I., Craig, W., M, Boyce, W., F., \& Pickett, W. (2004). Associations between overweight and obesity with bullying behaviors in school-aged children. Pediatrics, 113(5), 1187-1195.

Jeffery, A. N., Voss, L. D., Metcalf, B. S., Alba, S., \& Wilkin, T. J. (2005). Parents' awareness of overweight in themselves and their children: Cross sectional study within a cohort. British Medical Journal, 330(7481), 23-24.

Jelalian, E., Boergers, J., Alday, C. S., \& Frank, R. (2003). Survey of physician attitudes and practices related to pediatric obesity. Clinical Pediatrics, 42(3), 235-245.

Klein, D., Najman, J, Kohrman, AF, Munro, C. (1982). Patient characteristics that elicit negative responses from family physicians. Journal of Family Practice, 14, 881-888.

Klish. (1995). Childhood obesity: Pathophysiology and treatment. Acta Paediatrica Japonica, 37(1), 1-6.

Koblinsky, S. A., Guthrie, J. F., \& Lynch, L. (1992). Evaluation of a nutrition education program for Head Start parents. Journal of Nutrition, 24, 4-13.

Kumanyika, S. (2005). Obesity, health disparities, and prevention paradigms: Hard questions and hard choices. Preventing Chronic Disease: Public Health Research, Practice and Policy, 2(4), 1-9.

Kushner, R. (1995). Barriers to providing nutrition counseling by physicians: A survey of primary care practitioners. Preventive Medicine, 24(6), 543-545.

Larsen, L., Mandleco, B., Williams, M., \& Tiedeman, M. (2006). Childhood obesity: Prevention practices of nurse practitioners. Journal of the American Academy of Nurse Practitioners, 18(2), 70-79.

Leung, A., Robson, WL. (1990). Childhood obesity. Postgrad Medicine, 87, 123-133.

Lobstein, T., Baur, L., \& Uauy, R. (2004). Obesity in children and young people: A crisis in public health. Obesity Reviews, 5 (Suppl. 1), 4-104.

Maddox, G. L., \& Liedermann, V. (1969). Overweight as a social disability with medical implications. Journal of Medical Education, 44, 214-220.

Manus, H., \& Killeen, M. (1995). Maintenance of self-esteem by obese children. Journal of Child and Adolescent Psychiatric Nursing, 8, 17-27. 
Margarey, A., Daniels, L., \& Boulton, J. (2001). Prevalence of overweight and obesity in Australian children and adolescents: Reassessment of 1985 and 1995 data against new standard international definitions. Medical Journal of Australia, 174, 561-564.

Maroney, D., Golub, S. (1992). Nurses' attitudes toward obese persons and certain ethnic groups. Perceptual and Motor Skills, 75(3), 87-91.

Maynard, L. M., Galuska, D. A., Blanck, H. M., \& Serdula, M. K. (2003). Maternal perceptions of weight status of children. Pediatrics, 111(5), 1226-1231.

Mays, N., Pope, C., \& Popay, J. (2005). Details of approaches to synthesis: A methodological appendix to the paper: Systematically reviewing qualitative and quantitative evidence to inform management and policy making in the health field. Retrieved October 5, 2006, from http://www.sdo.Ishtm.ac.uk/methodsofsynthesis.html

McKey, A., \& Huntington, A. (2004). Obesity in pre-school children: Issues and challenges for community based child health nurses. Contemporary Nurse, 18(1-2), 145-151.

Mercer, S., \& Tessier, S. (2001). A qualitative study of general practitioners' and practice nurses' attitudes to obesity management in primary care. Health Bulletin, 59(4), 248253.

Miller, W., \& Rollnick, S. (1991). Motivational interviewing: Preparing people to change addictive behavior. New York, NY: Guilford Press.

Must, A., Hollander, S. A., \& Economos, C. D. (1999). Childhood obesity: A growing public health concern. Expert Review of Endocrinology and Metabolism, 1(2), 233-254.

National Health and Medical Research Council. (1997). Acting on Australia's weight: A strategic plan for the prevention of overweight and obesity. Canberra.

National Health and Medical Research Council. (2003). Dietary guidelines for children and adolescents in Australia incorporating the infant feeding guidelines for health workers. Canberra: Commonwealth of Australia.

National Public Health Partnership. (2005). Be active Australia: A framework for health sector action for physical activity. Melbourne, Victoria: Author.

Newacheck, P. W., Stoddard, J. J., Hughes, D. C., \& Pearl, M. (1998). Health insurance and access to primary care for children. New England Journal of Medicine, 338(8), 513519.

Northern Area Health Service. (n.d.). Growth assessment and action program (GAA). In Eat Well be Active. Appendix 3 - programs and terms at a glance. Retrieved November 23, 2005, from http://www.health.qld.gov.au/phs/Documents/shpu/29187h.pdf

O'Brien, S., Holubkov, R., \& Reis, E. (2004). Identification, evaluation, and management of obesity in an academic primary care center. Pediatrics, 114(2), 154.

O'Dea, J. (2003). Suggested activities to address body image issues, eating problems and child obesity prevention in school environments. Journal of the HEIA, 10(3), 2-12.

O'Dea, J. (2003). Differences in overweight and obesity among Australian schoolchildren of low and middle/high socioeconomic status. Medical Journal of Australia, 179, 63. 
Ogden, J., Bandara, I., Cohen, H., Farmer, D., Hardie, J., Minas, H., et al. (2001). General practitioners and patients models of obesity: Whose problem is it? Patient Education and Counseling, 44(3), 227-233.

Pearce, M., Boergers, J., \& Prinstein, M. (2002). Adolescent obesity, overt and relational peer victimization, and romantic relationships. Obes Res., 10, 386-393.

Pesa, J. A., Syre, T. R., \& Jones, E. (2000). Psychosocial differences associated with body weight among female adolescents: The importance of body image. Journal of Adolescent Health, 26(5), 330-338.

Pollard, C., Lewis, J., \& Miller, M. (2001). Start right-eat right award scheme: Implementing food and nutrition policy in child care centers. Health Educ Behav, 28(3), 320-330.

Price, J., Desmond, S., Krol, R., Snyder, F., \& O'Connell, J. (1987). Family practice physicians' beliefs, attitudes, and practices regarding obesity. Am J Prev Med., 3(6), 339-345.

Prochaska, J., \& DiClemente, C. (1986). Toward a comprehensive model of change. In W. Miller, Heather, N, (Ed.), Treating addictive behaviors: Processes of change (2 ed., pp. 3-27). New York: Plenum.

Prochaska, J., DiClemente, C., \& Norcross, J. (1992). In search of how people change: Application to addictive behaviors. American Psychologist, 47, 1102-1114.

Resnicow, K., Jackson, A., Wang, T., De, A. K., McCarty, F., Dudley, W. N., et al. (2001). A motivational interviewing intervention to increase fruit and vegetable intake through black churches: Results of the Eat for Life Trial. Am J Public Health, 91(10), 16861693.

Resnicow, K., \& Robinson, T. (1997). School-based cardiovascular disease prevention studies: Review and synthesis. Annals of Epidemiology, 7(Suppl. 1), 14-31.

Rollnick, S., Butler, C., McCambridge, J., Kinnersley, P., \& Elwyn, G., Resnicow, K. (2005). Consultations about changing behaviour. British Medical Journal, 331, 961-963.

Sallis, J. F., Patrick, K., Frank, E., Pratt, M., Wechsler, H., \& Galuska, D. A. (2000). Interventions in health care settings to promote healthful eating and physical activity in children and adolescents. Preventive Medicine, 31(Suppl. 2), 112-120.

Sangster, J., Chopra, M., \& Eccleston, P. (1998). Improving food-handling practices in child care centres. Health Promotion Journal of Australia, 8(3), 190-194.

Sangster, J., Eccleston, P., \& Stickney, B. (2003). Improving what's in the lunchbox in child care centres. Health Promotion Journal of Australia, 14, 171-174.

Schwartz, M. B., ONeal, C., Brownell, K., Blair, S. N., \& Billington, C. (2003). Weight bias among health professionals specialising on obesity. Obesity Research, 11, 10331039.

Serdula, M. K., Ivery, D., Coates, R. J., Freedman, D. S., Williamson, D. F., \& Byers, T. (1993). Do obese children become obese adults? A review of the literature. Preventive Medicine, 22(2), 167-177. 
Slee, P., \& Rigby , K. (1993). The relationship of Eysenck's personality factors and self esteem to bully-victim behaviour in Australian schoolboys. Personality and Individual Differences, 14(2), 371-373.

Slyper, A. H. (1998). Childhood obesity, adipose tissue distribution, and the pediatric practitioner. Pediatrics, 102(1), e4-9.

Sohn, W., Ismail, A. I., \& Tellez, M. (2004). Efficacy of educational interventions targeting primary care providers' practice behaviors: An overview of published systematic reviews. Journal of Public Health Dentistry, 64(3), 164-172.

St-Onge, M.-P., Keller, K. L., \& Heymsfield, S. B. (2003). Changes in childhood food consumption patterns: A cause for concern in light of increasing body weights. American Journal of Clinical Nutrition, 78, 1068-1073.

Stolley, M. R., Fitzgibbon, M. L., Dyer, A., Van Horn, L., KauferChristoffel, K., \& Schiffer, L. (2003). Hip-Hop to Health Jr., an obesity prevention program for minority preschool children: Baseline characteristics of participants. Preventive Medicine, 36(3), 320329.

Story, M., Neumark-Stzainer, D., Sherwood, N., Holt, K., Sofka, D., Trowbridge, F., et al. (2002). Management of child and adolescent obesity: Attitudes, barriers, skills, and training needs among health care professionals. Pediatrics, 110(1, part 2, Suppl.), 210-214.

Stradmeijer, M., Bosch, J., Koopsk, W., \& Seidell, J. (2000). Family functioning and psychosocial adjustment in overweight youngsters. International Journal of Eating Disorders, 27, 110-114.

Strauss, K. (1984). Personal and interpersonal characteristics associated with childhood obesity. Journal of Paediatric Psychology, 10, 337-343.

Strauss, R. (1999). Childhood obesity. Current Problems in Pediatrics, 29(1), 5-29.

Strauss, R. S. (2000). Childhood obesity and self-esteem. Pediatrics, 105(1), e15-22.

Strauss, R. S. (2002). Childhood obesity. Pediatric clinics of North America., 49(1), 175-201.

Stunkard, A., Foch, T., \& Hrubic, Z. (1986). A twin study of human obesity. JAMA, 256, 5154.

Teachman, B. A., \& Brownell, K. D. (2001). Implicit anti-fat bias among health professionals: Is anyone immune? International Journal of Obesity, 25, 1525-1531.

Teachman, B. A., Brownell, K.D. (2001). Implicit anti-fat bias among health professionals: Is anyone immune? International Journal of Obesity and Related Metabolic Disorders, $25,1525-1531$.

Tennant, S., Hetzel, D., \& Glover, J. (2003). A social health atlas of young south Australians. Adelaide: Openbook Print.

Tershakovec, A., Watson, M., Wenner, W. J., \& Marx, A. (1999). Insurance reimbursement for the treatment of obesity in children. $J$ Pediatr, 134, 573 -578. 
Thomas, H. (2006). Obesity prevention programs for children and youth: Why are their results so modest? Health Education Research, 21(6), 783.

Tremblay, M. (2003). The evolution of canada's "Supersize" Generation. Paper presented at the Continuing Medical Education and Professional Development conference: "Obesity: New Prescriptions for the Canadian Epidemic".

Vaska, V. L., \& Volkmer, R. (2004). Increasing prevalence of obesity in south Australian 4year olds:1995-2002. Journal of Pediatric Child Health, 40, 353-355.

VicHealth. (2003). Healthy eating and physical activity in early childhood services: Enhancing policy and practice in victorian family day care and long day care. A report to the eat well victoria partnership.

Wake, M., Salmon, L., Waters, E., Wright, M., \& Hesketh, K. (2002a). Parent-reported health status of overweight and obese Australian primary school children: A cross-sectional population survey. International Journal of Obesity, 26, 717-724.

Wake, M., Salmon, L., Waters, E., Wright, M., \& Hesketh, K. (2002b). Parent-reported health status of overweight and obese Australian primary school children: A cross-sectional population survey. International Journal of Obesity, 26, 717-724.

Wang, Z., Patterson, C. M., \& Hills, A. P. (2002). Association between overweight or obesity and household income and parental body mass index in Australian youth: Analysis of the Australian national nutrition survey. Asia Pacific Journal of Clinical Nutrition, 11(3), 200-205.

Wardle, J., Guthrie, C., Sanderson, S., Birch, L., \& Plomin, R. (2001). Food and activity preferences in children of lean and obese parents. International Journal of Obesity, $25,971-977$.

Whitaker, R., Wright, J., Pepe, M., Seidel, K., \& Dietz, W. (1997). Predicting obesity in young adulthood from childhood and parental obesity. N Engl J Med, 337, 869-873.

Wiesemann, A. (1997). Nutritional counseling in german general practices: A holistic approach. The American Journal of Clinical Nutrition, 65(6, Suppl.), 1957-1962.

Wisemandle, M. A., Maynard, L. M., Guo, S. S., \& Siervogel, R. M. (2000). Childhood weight, stature, and body mass index among never overweight, early-onset overweight, and late-onset overweight groups. Pediatrics, 106(1), e14.

World Health Organization. (1997). Obesity: Preventing and managing the global epidemic. Report of a who consultation on obesity. Geneva, Switzerland: World Health Organization.

World Health Organization. (2000). Obesity: Preventing and managing the global epidemic: Report of a WHO consultation. Geneva: WHO Consultation on Obesity. 